\title{
Las Cooperativas como Entidades con Fines No Lucrativos en México: regulación y características tributarias
}

\author{
Graciela Lara Gómez ${ }^{1}$ (c)
}

Recibido: 15 de julio de 2019 / Aceptado: 23 de septiembre de 2019 / Publicado: 7 de mayo de 2020

\begin{abstract}
Resumen. Con el artículo se buscó establecer si las cooperativas como integrantes del sector social de la economía son incluidas en las leyes como entidades no lucrativas y beneficiadas con incentivos tributarios. De manera que se realizó una aproximación teórica de las organizaciones sin fines de lucro y del sector social de la economía, acentuando la preeminencia de las cooperativas en el desarrollo económico y social. Para tal efecto fue seleccionado el método exegético, para explicar el alcance de las normas jurídicas y resoluciones de la Corte que avalan o rechazan su reconocimiento como entidades sin fines de lucro. Los resultados muestran que las legislaciones mexicanas reconocen la característica no lucrativa limitadamente, especialmente en el gravamen a la renta.
\end{abstract}

Palabras clave: Cooperativas; No lucro; Renta; Normas jurídicas.

Claves Econlit: H22; K00; K34; P13.

\section{[en] Cooperatives as non-profit entities in Mexico: Regulation and tax characteristics}

\begin{abstract}
The aim of this article is to look for if the cooperatives as members of the social sector of the economy are included in the laws as non-profit and beneficial entities with tax incentives. To this end, a theoretical approach has been made to nonprofit organizations and the social sector of the economy, emphasizing the pre-eminence of cooperatives in economic and social development. We use the exegetical method to explain the scope of the legal norms and the resolutions of the Court. The results show that the Mexican legislation recognizes the non-profit characteristic in a limited way, especially in the income tax.

Keywords: Cooperatives; Non-profit; Income; Legal norms.
\end{abstract}

Sumario. 1. Introducción. 2. Metodología. 3. Aproximación teórica. 4. Discusión. 5. Conclusiones. 6. Referencias bibliográficas. 7. Anexo legislativo.

Cómo citar: Lara Gómez, G. (2020) Las Cooperativas como Entidades con Fines No Lucrativos en México: regulación y características tributarias. REVESCO. Revista de Estudios Cooperativos, vol. 134, e69161. https://dx.doi.org/10.5209/REVE.69161.

\section{Introducción}

El cooperativismo representa una doctrina económica y social que nace como una necesidad histórica para asegurar la sobrevivencia y enfrentar problemas comunes. Con tal perspectiva se defiende la idea de que, a través del trabajo, el consumo, la producción y la solidaridad de las personas, es posible resolver problemáticas comunes. Por ende, la cooperativa representa una alternativa viable para contribuir al avance empresarial colectivo y a la cohesión social que permite a sus miembros tomar el mando de su propio desarrollo.

Por lo mencionado, resulta relevante el análisis de las cooperativas por sus características propias, que reconocen su gestión orientada al bien común y a la solidaridad, que es un contrapeso a la acumulación del capital. De manera que se determinó como objetivo general: establecer si las cooperativas como parte del sector social de la economía en México, son reconocidas en las normas jurídicas como entidades sin fines de lucro y en consecuencia reciben incentivos tributarios.

Para este artículo fue elegida una aproximación teórica centrada en las entidades no lucrativas y las cooperativas, destacando sus particularidades y esbozando la perspectiva que incluye a las empresas de la economía social en el sector no lucrativo. En seguida fueron identificadas las normas jurídicas que regulan a dichas organizaciones en México, observando que son integradas en la

\footnotetext{
Universidad Autónoma de Querétaro, México

Dirección de correo electrónico: glara@uaq.mx.
} 
Constitución como parte del sector social de la economía y reguladas por dos legislaciones federales: la primera es la Ley General de Sociedades Cooperativas (2018) y la segunda se denomina Ley para Regular las Actividades de las Sociedades Cooperativas de Ahorro y Préstamo (LRASCAP, 2009).

Enseguida, se precisó que la metodología se regiría por el método exegético, con lo que fue posible comprender el alcance de las leyes y la interpretación de la Corte ante el contexto legislativo que prevalece en México. Finalmente, se agregó un apartado de discusión con el que se bosqueja el rol de las cooperativas a la luz del acto cooperativo y su tratamiento en la Ley del Impuesto Sobre la Renta.

Por último, los resultados apuntan al reconocimiento legal de cooperativas, por su contribución en el desarrollo social de México, atribuyéndoles en las normas jurídicas la característica no lucrativa, pero integrando ciertas limitaciones que pueden ser explicadas a través de las resoluciones de la Corte y la realidad que se vive en el sector empresarial en México.

\section{Metodología}

La finalidad del artículo fue llevar a cabo un análisis de las cooperativas mexicanas, a efecto de determinar si dichas sociedades por ser incluidas en el sector social de la economía, son reconocidas como entidades sin fines de lucro en los ordenamientos constitucionales y legales. Asimismo, se buscó establecer cuáles son los beneficios que pudieran derivar de tal calificación en las normas tributarias.

Con el planteamiento previo, se precisó el objetivo general como sigue: establecer si las cooperativas como parte del sector social de la economía, son reconocidas en las normas jurídicas como entidades sin fines de lucro y en consecuencia reciben beneficios tributarios.

Para el desarrollo de la investigación se atendió al método exegético, que se sustentó en la revisión doctrinal, en el análisis de las leyes en materia cooperativa y del Impuesto Sobre la Renta vigentes, así como en las resoluciones de la Corte. Con ello, se buscó identificar los argumentos que se defienden, para asignar la característica no lucrativa a las cooperativas.

\section{Aproximación teórica}

Se ha respaldado reiteradamente que las cooperativas deben ser consideradas como entidades sin fines de lucro, dada su finalidad social. Se ha demostrado que tales figuras jurídicas influyen positivamente en las comunidades donde se ubican, por lo que su actividad debe ser incentivada a través de leyes que las promuevan y beneficien. Por lo que, en este apartado se presentan las vertientes teóricas que permiten comprender las características del sector no lucrativo, enfatizando la aportación doctrinal referida al acto cooperativo y acentuando el rol que asumen tales sociedades en el sector social de la economía.

\subsection{Las entidades con fines no lucrativos}

Para dilucidar la característica no lucrativa, fue necesario precisar lo que se entiende como lucro. En este sentido el Diccionario de la Real Academia Española (2014:1) lo define como "Ganancia o provecho que se saca de algo", mientras que lo lucrativo refiere a "lo que produce utilidad o ganancia”. Por ende, lo 'no lucrativo' presupone la inexistencia o ausencia de utilidad o ganancia.

Consecuentemente, una Entidad No Lucrativa "es una entidad privada que, en virtud de sus reglas constitutivas, no puede distribuir sus beneficios a las personas que la controlan, teniendo que destinarlos bien a la realización de sus objetivos (o a la reinversión), bien a la ayuda a personas que no ejerzan ningún control sobre la organización" (Wolters Kluwer, s.f., 1).

En este orden de ideas, Marcuello (2006: 56) rescata la definición propuesta por Hansmann, indicando que: "las organizaciones no lucrativas son organizaciones privadas que tienen prohibido el reparto de beneficios entre los miembros y/o promotores". A pesar de lo citado, se entiende que tales organizaciones llevan a cabo actividades económicas que pueden mostrar resultados financieros favorables, los que no tienen como finalidad ser distribuidos en proporción de un capital aportado, sino que se predestinarán al logro del objetivo social por el que dichas entidades fueron creadas.

Según Ruiz (2001) en el sector no lucrativo persisten situaciones que no permiten un análisis puntual y riguroso del mismo, entre las razones que menciona, se encuentran: la vaguedad conceptual, su historia, su ambivalencia jurídica y el desconocimiento sobre su estadística. Está problemática es avalada por Chaves \& Monzón (2001), quienes dicen que no existe consenso acerca de dónde debe incluirse al sector no lucrativo, ya que algunos opinan que debe adscribirse al 'tercer sector', o bien al denominado 'sector no lucrativo', que también es designado como 'sector asociativo' o 'tercer sistema social'.

Al respecto, Marcuello (2006) señala que las organizaciones sin fines de lucro son reconocidas con denominaciones diversas, entre ellas: organizaciones voluntarias, organizaciones de economía social, tercer 
sector, organizaciones independientes, organizaciones benéficas, además de organizaciones no gubernamentales.

Chaves \& Monzón $(2005,2001)$ mencionan dos tendencias principales que cimientan la existencia del sector no lucrativo: la primera con raíz francófona, reconoce al sector no lucrativo como parte del 'tercer sector' -identificado con la Economía Social-, mientras que la segunda es de carácter anglosajón y se relaciona con las Nonprofit organizations. Esta última expresión se ha utilizado para describir al sector no lucrativo privado, que se integra por fundaciones y asociaciones. En este sentido, Ruiz (2001) indica que establece cinco criterios para calificar a las entidades del tercer sector, a partir de cinco rasgos característicos:

1. Estar organizada,

2. Ser privada,

3. No repartir los beneficios entre los propietarios o administradores,

4. Gozar de autonomía, y

5. Tener un marcado grado de participación voluntaria.

Por su parte, Perdomo (2007) señala que las organizaciones no lucrativas tienen peculiaridades propias que las distinguen de otras, como las empresas de negocios y las gubernamentales. Entre dichas características diferenciadoras se encuentra que tienen un rol relevante en la cohesión social, generan empleo y riqueza, promueven valores sociales como la democracia y la participación ciudadana, además de que estimulan la solidaridad y las causas altruistas, por lo que la ausencia de beneficios económicos es su característica esencial, ya que llevan a cabo actividades gratuitas o cuasi-gratuitas, siendo las donaciones una fuente principal de ingresos. Así, Marcuello (2006) dice que este tipo de organizaciones son la respuesta desde la sociedad para atender necesidades de sus miembros.

Por tanto, existe una importante variedad de organizaciones que pueden ser clasificadas como no lucrativas, estableciendo que, desde una concepción europea, no únicamente se refieren a las fundaciones o asociaciones, sino que su rol va más allá de la actividad para el beneficio social, pues también llevan a cabo actividades de carácter económico. Al respecto, Salinas \& Rubio (2001) aclaran que desde la perspectiva española se hace una diferenciación entre las sociedades cooperativas, las mutualistas y las organizaciones no lucrativas, indicando que estas últimas son complejas y difíciles de definir, pero se coincide en que poseen la capacidad para proporcionar respuestas a las necesidades y demandas sociales, presentando un importante potencial en la creación de puestos de trabajo, asumiendo actividades cuya responsabilidad corresponde a la administración pública.

Además, Salinas \& Rubio (2001) afirman que las organizaciones no lucrativas tienden a realizar actividades económicas que las debe conducir a la integración de empresas sociales más formalizadas, lo que es concordante con lo expuesto por Defourny \& Nyssens (2012) quienes conciben un nuevo resurgimiento de la Economía Social desde la década de 1980, lo que consideran es perceptible a través de nuevos y diversos tipos de empresas y otras organizaciones de participación colectiva que han surgido a raíz de las grandes transformaciones del sistema económico imperante, con iniciativas similares a las cooperativas, particularmente en el ámbito de servicios personales e integración laboral.

Recuperando la perspectiva española, Ruiz (2001) considera que el sector no lucrativo se integra por: asociaciones, fundaciones, cooperativas, mutualidades de previsión social, centros de enseñanza, clubes deportivos, cajas de ahorros con obra social y hospitales. Mientras que García (2017) presenta un listado de las entidades que pueden ser reconocidas como no lucrativas, indicando que tales organizaciones únicamente pueden constituirse legalmente bajo la figura jurídica de fundaciones, asociaciones y cooperativas sin ánimo de lucro (Tabla 1):

Tabla. 1. Organizaciones no lucrativas.

\begin{tabular}{|l|l|}
\hline Tipo & Características \\
\hline Asociaciones de hecho & $\begin{array}{l}\text { Incluye agrupaciones informales, como peñas y cofradías no } \\
\text { constituidas legalmente. }\end{array}$ \\
\hline $\begin{array}{l}\text { Mutuas y mutualidades o } \\
\text { Montepíos de Previsión Social }\end{array}$ & $\begin{array}{l}\text { Son agrupaciones constituidas para proteger bienes o } \\
\text { propiedades, o bien crear fondos de previsión. }\end{array}$ \\
\hline Asociaciones religiosas & $\begin{array}{l}\text { Son asociaciones regidas por el Derecho Canónico, incluye a } \\
\text { las asociaciones de familias cristianas, institutos religiosos, } \\
\text { entre otros. }\end{array}$ \\
\hline
\end{tabular}




\begin{tabular}{|l|l|}
\hline Asociaciones socioculturales & $\begin{array}{l}\text { Son entidades no lucrativas con finalidad específica centrada } \\
\text { en la promoción de actividades sociales y culturales. }\end{array}$ \\
\hline $\begin{array}{l}\text { Corporaciones sociales de } \\
\text { Derecho Público }\end{array}$ & $\begin{array}{l}\text { Son organizaciones que velan por los intereses de sus } \\
\text { agremiados, por ejemplo, los colegios de profesionales. }\end{array}$ \\
\hline Fundaciones & $\begin{array}{l}\text { Son entidades con personalidad jurídica, con recursos } \\
\text { provenientes de rentas patrimoniales y que sirven a fines de } \\
\text { interés público. }\end{array}$ \\
\hline Entidades de Economía Social & $\begin{array}{l}\text { Incluye a las cooperativas y a las sociedades anónimas } \\
\text { laborales. }\end{array}$ \\
\hline Otras & $\begin{array}{l}\text { Partidos políticos, sindicatos, centrales patronales, clubes } \\
\text { deportivos y obra social de cajas de ahorro. }\end{array}$ \\
\hline
\end{tabular}

Fuente: Elaborado con base en García (2017).

Entonces, las entidades no lucrativas adoptan diversas formas asociativas, incluidas las que quedan comprendidas en el marco de la Economía Social (Chaves \& Monzón, 2001), pues que como lo indica Monzón (2013) es ahí donde surgen las empresas sociales, las que son creadas como entidades privadas, integradas por grupos de ciudadanos que participan directamente y tienen poder de decisión que no se apoya en la cantidad aportada al capital, además de que se limita la distribución de excedentes y tienen una finalidad explicita de beneficiar a la comunidad que son parte de colectivos vulnerables o en riesgo de exclusión social.

Para lograr un acercamiento adicional a la definición de las organizaciones no lucrativas, desde la perspectiva de la teoría contable, se recurrió a las Normas de Información Financiera (NIF), encontrando que dichas organizaciones han sido registradas con la denominación de entidades con propósitos no lucrativos en la NIF A-3, donde se propone la siguiente definición:

"Es aquella unidad identificable que realiza actividades económicas, constituida por la combinación de recursos humanos, materiales y financieros, coordinados por una autoridad que toma decisiones encaminadas a la consecución de los fines para los que fue creada, y que no resarce económicamente a sus donantes" (NIF, 2018: 32).

Como puede observarse, el texto es limitado, ya que pareciera que únicamente se refiere a las entidades que reciben donativos, como las organizaciones filantrópicas, pero en la práctica no es así. Para abundar sobre el particular, se agregan algunos ejemplos de este tipo de personas jurídicas, entre las que se cuentan: los dispensarios, orfanatos, asilos, centros de investigación, sindicatos, colegios profesionales y entidades que lleven a cabo actividades culturales, artísticas o científicas.

Es preciso señalar que la normativa contable no menciona expresamente a las cooperativas, pero indica que las entidades no lucrativas como parte de su actividad proporcionan bienes y servicios fijando precios iguales o más bajos que los de su costo o sin cargo alguno; lo que es equiparable a las actividades que se realizan través de las cooperativas de producción y consumo en México.

\subsection{Las Cooperativas como entidades con fines no lucrativos}

La Alianza Cooperativa Internacional (ACI, 1995: 1) ha definido a las cooperativas como: "una asociación autónoma de personas que se han unido voluntariamente para hacer frente a sus necesidades y aspiraciones económicas, sociales y culturales comunes por medio de una empresa de propiedad conjunta y democráticamente controlada".

Como deriva de la definición proporcionada por la ACI, no se incluye la característica no lucrativa, lo que puede deberse al reconocimiento de la importante complejidad en las legislaciones de los diferentes países. En este sentido, Fici (2015) señala que diversas Constituciones en el mundo incluyen la función social de las cooperativas; mientras que, en las legislaciones e instituciones de Europa, se reconoce a la cooperativa como entidad de la economía social y que es el sector público a través del Estado el responsable de fomentarlas. Por tanto, se trata de que la identidad jurídica de la cooperativa quede plasmada en la constitución y en las leyes con un tratamiento privilegiado y de tutela particular.

En este sentido, se advierte en las legislaciones latinoamericanas la inclusión de la expresión acto cooperativo, concepto que se atribuye a Antonio Salinas Puente, jurista mexicano que en 1954 propuso tal expresión (Mora, 2004), siendo incorporada en diversas legislaciones latinoamericanas. 
El acto cooperativo se define como: "El supuesto jurídico, ausente de lucro y de intermediación, que realiza la organización cooperativa en cumplimiento de un fin preponderantemente económico y de utilidad social" (en Mora, 2004: 2). En un sentido similar, Naranjo (2016: 6) lo precisa como "El realizado entre los socios y la cooperativa, en el marco del cumplimiento del objeto social de la misma". En esta propuesta se dejan de lado los negocios que con terceros lleve a cabo la sociedad. Asimismo, se señala que las características atribuidas al acto cooperativo se identifican con la voluntariedad, la igualdad, la unilateralidad, la solidaridad y el carácter no lucrativo.

Naranjo (2016) acentúa que las organizaciones no lucrativas obtienen beneficios, pero no significa que sea ganancia o utilidad, ya que la misma resulta de las operaciones con sus miembros, las que son necesarias para subsistir. Tal escenario es diferente al que persiste en las empresas de capitales, donde la búsqueda de las utilidades es el objetivo primordial. Por su parte, Cracogna (2009) y Mora (2004) destacan la propuesta de Salinas Puente, diciendo que el acto cooperativo implica un acto de organización ausente de lucro y de intermediación, que integra la finalidad social.

Asimismo, debe subrayarse que las cooperativas fundamentan su actuación en principios y valores, lo que es una clara diferencia con otras sociedades de tipo lucrativo. Es por lo que en el tercer principio Participación económica de los miembros-, se menciona que las aportaciones que efectúan los miembros son equitativas, por lo que el capital se controla democráticamente y una parte del mismo es propiedad común de la cooperativa. También se contempla la posibilidad de que los miembros reciban una compensación limitada por el capital suscrito y que destinen parte de los remanentes a la creación de reservas (ACI, 1995).

Por tanto, puede afirmarse que las cooperativas no buscan el lucro, sino realizar actividades económicas que les permita tener la sustentabilidad financiera necesaria para lograr el objetivo por el que fueron creadas, lo que quiere decir que los miembros serán beneficiados prioritariamente.

Enseguida se mencionan algunas de las características que para las cooperativas son señaladas por Lara (2011: 31-32):

- Realizan actividades económicas.

- $\quad$ La adhesión de los miembros es libre y voluntaria.

- Son organizaciones autónomas de los poderes públicos, pero pueden participar con ellos en actividades económicas o en la obtención de recursos.

Se caracterizan por su integración democrática (un socio = un voto).

- $\quad$ La dirección y control de la empresa queda normalmente a cargo de los socios.

- $\quad$ En la distribución de excedentes se prioriza el trabajo de las personas sobre el capital.

- $\quad$ Las reservas creadas con los excedentes, generalmente se destinan a fines sociales.

- Como empresas de personas y no de capitales se busca asegurar la viabilidad económica y el beneficio social.

A los rasgos citados puede agregarse que son organizaciones que en su gestión ponen en práctica valores y principios que forman parte de la filosofía del cooperativismo, pero que además contribuyen con la comunidad en temas de sustentabilidad, equidad de género, erradicación de la pobreza, entre otros de igual relevancia.

En este sentido Lara (2011) dice que las cooperativas favorecen el desarrollo empresarial, permitiendo que sus integrantes logren ser artífices de su propio destino. Consiguientemente, la cooperativa es en sí misma una forma de innovación con capacidad de dinamizar realidades locales, ya que representa un instrumento capaz de generar mejoras económicas y sociales donde el inversor tradicional no participa o no tiene interés en participar, lo que en buena medida justifica su valoración como organización no lucrativa.

Por su parte, Fici (2015) reitera que, en diversas Constituciones nacionales, se asigna a las cooperativas la particularidad de realizar una función social. Por lo que tales sociedades presentan una identidad jurídica diferente de otras, esto significa que el régimen legal requiere de una idoneidad específica, debiendo considerar disposiciones congruentes a su finalidad económica - social, como el fin de la mutualidad, su estructura democrática, altruismo, solidaridad y primacía de la persona sobre el capital. Rodrigo (2003) comparte que prevalece un enfoque social en las cooperativas, indicando que en buena parte el patrimonio social es obtenido por el esfuerzo de los miembros para luego ser revertido a la comunidad.

Por tanto, se ha considerado que por particularidades como la finalidad social que deriva en beneficio tangibles para los asociados y las comunidades, es necesario incentivar a las organizaciones sin fines de lucro, a través de apoyos de tipo tributario para liberarlas del pago de gravámenes como el que se impone en materia de renta o utilidades, a efecto de darle un significado a la característica no lucrativa. Lo que es congruente con la defensa reiterada de un tratamiento tributario favorable para las cooperativas, lo que estaría apoyado en la justicia contributiva y la idoneidad del modelo social (Fici, 2015; Pastor, 2012; Merino, 2009). 


\section{Discusión}

El estudio se enfoca en las cooperativas, las que forman parte del sector social de la economía en México y que se hallan entre las entidades más representativas del sector, ya que por su medio se promueve la producción, el consumo y los servicios financieros para los sectores de la población con carencias económicas. De manera que, se esclarece la concepción legal de este tipo de sociedades y su especificidad como entidades no lucrativas, así como los incentivos que el Estado contempla para su fomento.

En consecuencia, se expone el rol de las cooperativas como entidades no lucrativas, desde la perspectiva de la normativa mexicana en el tema cooperativo y la que corresponde al gravamen a la renta; recalcando los criterios de la Corte que avalan la característica lucrativa o no lucrativa de las tres clases de cooperativas reconocidas en México.

\subsection{Las entidades no lucrativas en México: Su fundamento constitucional y legal}

En México la concepción de entidades no lucrativas es muy cercana a la visión española a que se refiere Ruiz (2001) quien, entre otras organizaciones, incluye a las cooperativas. Para tales sociedades, la legislación de la materia prevé la posibilidad de reinvertir los excedentes o distribuirlos entre los socios (Ley General de Sociedades Cooperativas, 2018), lo que es contrario a las características propias de las entidades del tercer sector, que tiene como característica, el no reparto de excedentes.

Es en la Constitución Política de los Estados Unidos Mexicanos (2018) que se reconoce la existencia del sector social de la Economía, enunciando a las entidades que lo conforman, entre las que se encuentran las cooperativas, que son las organizaciones más representativas de la Economía Social. Es necesario señalar que, en la Constitución citada no se define a las entidades no lucrativas, pero en cambio se menciona la obligatoriedad del Estado de favorecer su organización y expansión a través del impulso al sector social.

Es en el artículo 25 párrafo octavo, se indican las formas jurídicas que integran al sector social, entre ellas se incluye a: los ejidos, organizaciones de trabajadores, cooperativas, comunidades, empresas que pertenezcan mayoritaria o exclusivamente a los trabajadores y, aquellas formas de organización social para la producción, distribución y consumo de bienes y servicios socialmente necesarios. Además de las aludidas, en el dispositivo jurídico se observan otras formas organizacionales enfocadas a actividades que no persiguen el lucro, tales como las dedicadas a actividades científicas, educativas, religiosas y de beneficencia (Constitución Política de los Estados Unidos Mexicanos, 2018).

Retomando la figura cooperativa, se puede afirmar que el origen jurídico de la cooperativa en México fue contemplado por primera vez en el Código de Comercio y luego en la Ley General de Sociedades Mercantiles (LGSM, 2018), donde fue concebida como una sociedad mercantil. Ante esta calificación, podría decirse que al encontrarse la sociedad cooperativa y otras de carácter lucrativo en la misma legislación, deberían tener similitudes importantes, pero esto no es así, de hecho, son diametralmente diferentes, pues la primera se centra en buscar los beneficios de las personas y la segunda en el capital, es decir en la generación de utilidades.

En este sentido, Izquierdo (2012) dice que en las normas cooperativas ha prevalecido una importante confusión sobre la naturaleza jurídica de tales sociedades, ya que esencialmente no son sociedades mercantiles. No obstante, lo señalado por la autora, como se ha visto, las cooperativas son legalmente mercantiles, al estar contenidas en la legislación específica para tales entidades (LGSM, 2018).

No obstante que la Constitución no atribuye expresamente la característica no lucrativa a las entidades del sector social de la economía, en el artículo 2 de la Ley General de Sociedades Cooperativas (2018: 1) se presentan elementos específicos de la sociedad cooperativa, como los referidos a la práctica de principios y valores para el desarrollo de la actividad económica.

De manera que la norma legal define a la cooperativa como sigue:

"La sociedad cooperativa es una forma de organización social integrada por personas físicas con base en intereses comunes y en los principios de solidaridad, esfuerzo propio y ayuda mutua, con el propósito de satisfacer necesidades individuales y colectivas, a través de la realización de actividades económicas de producción, distribución y consumo de bienes y servicios" (Ley General de Sociedades Cooperativas, 2018: 1).

Como puede verse, la definición citada no contiene expresamente la característica no lucrativa, pero si se contiene en el artículo 5 de la Ley General de Sociedades Cooperativas (2018: 2) el 'acto cooperativo', que es un concepto relacionado con la organización y funcionamiento al interior de dichas sociedades. El precepto legal enuncia lo siguiente:

"Artículo 5.- Se consideran actos cooperativos los relativos a la organización y funcionamiento interno de las sociedades cooperativas.” (Ley General de Sociedades Cooperativas, 2018: 2) 
Con lo mencionado, puede expresarse que es en el acto cooperativo que se fundamenta la vocación no lucrativa de las organizaciones del sector social. Asimismo, la visión mencionada en la Ley General de Sociedades Cooperativas (2018) reconoce la actividad empresarial y la distribución de beneficios, por lo que surge una clara separación de las asociaciones de beneficencia con enfoque anglosajón (Nonprofit organizations) y de las Empresas Sociales como las cooperativas.

En cuanto a los tipos de cooperativas mencionados en la legislación mexicana, en el artículo 21 de la Ley General de Sociedades Cooperativas (2018), se expresa la existencia de tres tipos de cooperativas: de consumidores de bienes y/o servicios, de productores de bienes y/o servicios, y de ahorro y préstamo.

Entre otras disposiciones, se reitera la posibilidad de que los socios reciban rendimientos, lo que queda en el poder de decisión de la asamblea, determinando la distribución de los rendimientos anuales (artículo 36$\mathrm{X}$ ), los que se prorratearán de acuerdo a la participación de los socios (artículo 6) o del trabajo aportado en las cooperativas de productores (artículo 28) (Ley General de Sociedades Cooperativas, 2018). Como puede observarse, la distribución de excedentes es una práctica permitida, pero considerando la creación de reservas y la necesidad de priorizar la finalidad social. Por su parte, la Suprema Corte de Justicia de la Nación (SCJN) ha clarificado las características de este tipo de sociedades, a través de los Tribunales Colegiados de Circuito, destacando el poder la asociación y la contribución al desarrollo económico y reconociendo el derecho de los asociados de recibir los beneficios económicos, inclusive a través del reparto de utilidades (SCJN, 2012).

Con lo anterior, es claro que las cooperativas realizan actos cooperativos y pueden presentar resultados positivos en sus estados financieros, con motivo de sus actividades económicas, lo que daría lugar a destinar dichos remanentes a finalidades propias de las cooperativas o inclusive a su distribución entre los socios. Tal tratamiento para los remanentes pareciera un contrasentido, respecto a la propuesta de Hansmann, quien considera que en las entidades no lucrativas se conserva la prohibición de distribuir utilidades.

Adicionalmente, pudo establecerse que en la Ley General de Sociedades Cooperativas (2018), solo se incluye literalmente la designación no lucrativa, a las Federaciones y Confederaciones que integran a las Sociedades de Ahorro y Préstamo, conminándolas a la adopción de la naturaleza cooperativa sin finalidad de lucro. Es así como en el artículo 78 Bis 3, se indica lo siguiente:

"Las Federaciones y la Confederación, como organismos cooperativos de integración y representación de las Sociedades Cooperativas de Ahorro y Préstamo, serán instituciones de interés público, con personalidad jurídica y patrimonio propios, adoptarán jurídicamente la naturaleza Cooperativa, sin fines lucrativos." (Ley General de Sociedades Cooperativas, 2018: 21).

Por tanto, tal como lo señalan Pastor (2012) y Merino (2009), es fundamental reconocer la idoneidad del modelo social a través de beneficios como la liberación de gravámenes, más todavía los que de manera directa inciden en los sujetos del tributo, como es el relativo a la imposición a la renta. En este sentido, pudo observarse que el artículo 91 (Ley General de Sociedades Cooperativas, 2018) incluye un supuesto de liberación de impuestos y derechos que aplicaría en el ámbito federal con motivo de la constitución de la sociedad, señalando que para tal efecto la autoridad competente tendrá la obligación de expedir las resoluciones fiscales que procedan.

Además de lo indicado, en la LRASCAP (2009: 2) se reconoce la vocación no lucrativa de las Cooperativas de Ahorro y Préstamo, citado en el siguiente texto:

"Artículo 2.- Para efectos de la presente Ley se entenderá por:

Sociedad o Sociedad Cooperativa de Ahorro y Préstamo: en singular o plural, a las sociedades constituidas y organizadas conforme a la Ley General de Sociedades Cooperativas, independientemente del nombre comercial, razón o denominación social que adopten, que tengan por objeto realizar operaciones de ahorro y préstamo con sus Socios, y quienes forman parte del sistema financiero mexicano con el carácter de integrantes del sector social sin ánimo especulativo y reconociendo que no son intermediarios financieros con fines de lucro" (LRASCAP, 2009: 2).

Con lo analizado es posible afirmar que en la Ley General de Sociedades Cooperativas (2018) y la LRASCAP (2009) se contempla la característica no lucrativa que distingue a las cooperativas, con la mención del acto cooperativo y con el reconocimiento para las cooperativas de ahorro y préstamo de ser intermediarios financieros que no persiguen el lucro.

No obstante, como se verá en el siguiente apartado, además de las cooperativas de ahorro y préstamo, las cooperativas de consumo también son consideradas como personas morales no lucrativas, lo que representa un reconocimiento importante de la actividad que dichas sociedades llevan a cabo. 


\subsection{Las cooperativas y el gravamen a la renta}

Es en la Ley del Impuesto sobre la Renta (2016) donde se confirma de manera explícita cuáles son las entidades que forman parte del sector no lucrativo, es decir, se incluyen en el Título III, Del Régimen de las Personas Morales con fines no Lucrativos. Entre las personas morales que las integran se encuentran enunciativamente: los sindicatos y organismos que los agrupen, las asociaciones y sociedades con fines filantrópicos, culturales, deportivas, educativos, tecnológicos y aquellas autorizadas para recibir donativos, las cooperativas de ahorro y préstamo y consumo, así como las cajas de ahorro de acuerdo con la legislación laboral, los partidos políticos, el Estado en sus tres niveles de gobierno (Federal, Estatal y Municipal) y los organismos descentralizados, colegios y agrupaciones de profesionistas, entre otros (Artículo 79, Ley del Impuesto Sobre la Renta, 2016).

Como se recordará, la característica no lucrativa no se señala expresamente en la Constitución, por lo que de acuerdo con las leyes de la materia se puede entender incluida dicha característica a través del acto cooperativo (Ley General de Sociedades Cooperativas, 2009). Por su parte, en la LRASCAP (2009) se menciona claramente que la actividad de intermediación financiera que llevan a cabo las cooperativas de ahorro y préstamo es sin fines de lucro.

Adicionalmente, debe comentarse que si bien la normativa contable (NIF A-3) incluye a las Entidades con propósitos no lucrativos y contempla que realizan actividades para los fines por las que fue creada, también menciona que en ningún momento retribuye económicamente a sus donantes (NIF, 2018). Por tanto, dichas disposiciones no tienen un alcance mayor, ya que no son retomadas por la legislación fiscal para fines del Impuesto Sobre la Renta.

De manera que, las cooperativas de ahorro y préstamo, así como las de consumo quedan contempladas en el Impuesto Sobre la Renta, tal como se puede ver en el artículo 79 - VII (Ley del Impuesto Sobre la Renta, 2016: 93-94).

"Artículo 79. No son contribuyentes del impuesto sobre la renta, las siguientes personas morales:

VII. Sociedades cooperativas de consumo.

XIII. Las instituciones o sociedades civiles, constituidas únicamente con el objeto de administrar fondos o cajas de ahorro, y aquéllas a las que se refiera la legislación laboral, así como las sociedades cooperativas de ahorro y préstamo a que se refiere la Ley para regular las actividades de las sociedades cooperativas de ahorro y préstamo" (Ley del Impuesto Sobre la Renta, 2016: 93-94).

Como puede verse en el texto anterior, son dos las cooperativas que se clasifican como no contribuyentes del tributo, pero además en la Ley del Impuesto Sobre la Renta (2016: 93) se prescribe que los organismos que integren a las sociedades cooperativas, se regirán por el mismo Título III. Por tanto, en el artículo 70 VIII se puede constatar que son considerados como personas morales sin fines de lucro, tal como se menciona enseguida:

“(...)

VIII. Organismos que conforme a la Ley agrupen a las sociedades cooperativas, ya sea de productores o de consumidores." (Ley del Impuesto Sobre la Renta, 2016: 93).

Debe destacarse que tal como lo prescribe el texto legal, están liberados del Impuesto Sobre la Renta, exclusivamente los organismos que agrupan a las cooperativas de productores y consumidores, no así los que integran a las cooperativas de ahorro y préstamo. Sin embargo, como ya se ha mencionado, en la Ley General de Sociedades Cooperativas en su artículo 78 Bis 3, se indica que los organismos que agrupen a las cooperativas de ahorro y préstamo se constituirán como personas morales sin fines de lucro.

De tal manera que la Ley del Impuesto Sobre la Renta (2016) señala como entidades no lucrativas a:

- Las cooperativas de consumo,

- $\quad$ Las cooperativas de ahorro y préstamo, y

- Los organismos que agrupen a las cooperativas de producción y de consumo, entre los que pueden considerarse, las uniones, federaciones y confederaciones.

Por tanto, a pesar de que las cooperativas se encuentran en la Constitución mexicana como integrantes del sector social de la economía y que la Ley General de Sociedades Cooperativas (2018) reconoce su finalidad social, tales normas no se encuentran alineadas con la Ley del Impuesto Sobre la Renta (2016), lo que resulta en que parcialmente las cooperativas sean reconocidas como entidades sin fines de lucro, ya que se deja fuera a las cooperativas de producción.

En este orden de ideas, las cooperativas de producción se integran en la Ley del Impuesto Sobre la Renta (2016) como personas morales obligadas al pago del impuesto, en términos similares que el resto de las 
sociedades lucrativas. Asimismo, debe aclararse que esta clase de sociedades se clasifican de acuerdo a su actividad centrada en la producción de bienes o en la de servicios. A este respecto, debe mencionarse que la Ley del Impuesto Sobre la Renta (2016) también diferencia entre ambas actividades, dado que las cooperativas de producción dedicadas a actividades primarias (pesca, silvicultura, agricultura y ganadería) tendrían beneficios tributarios expresados a través de reducciones y exenciones del impuesto, lo que no se aplica para las dedicadas a los servicios, por lo que estas últimas quedan sujetas al gravamen a la renta del $30 \%$ de la misma manera que las sociedades lucrativas.

En este sentido, la Corte ha dictado una resolución que indica que distinguir ambas actividades (bienes y servicios) en las cooperativas de producción, no viola el principio de equidad tributaria, toda vez que las cooperativas realizan actividades que tienen finalidades diferentes, pues las dedicadas a los servicios deben ser gravadas por los ingresos obtenidos, debido a que:

“... están encaminadas a prestar asistencia profesional, técnica, académica o científica, y no a producir bienes relacionados con las actividades enumeradas en líneas precedentes, quedando así justificado el trato desigual que se otorga a ambos tipos de sociedades cooperativas de producción." (SCJN, 2002: 297).

Por tanto, se confirma que el tratamiento que se otorga a las cooperativas de producción ha sido reiteradamente avalado por la Corte, a través de resoluciones que insisten en la diferenciación entre las actividades, gravando en materia de renta a ambas, pero en mayor medida a las que se dedican a la producción de servicios, equiparándolas con las empresas de capitales. Adicionalmente, se ha argumentado en la resolución 174/2005 que la exención aplicable a las cooperativas de consumo cumple con el principio de equidad, ya que las cooperativas de producción y consumo son sujetos pasivos que se ubican en situaciones objetivamente diferentes desde la perspectiva social y económica. Tales argumentos se extraen de la resolución citada, como sigue:

“(...)

Así, mientras la finalidad de las sociedades cooperativas de consumo consiste en suministrar a sus miembros, a precios módicos, los artículos o servicios que requieren para satisfacer sus necesidades, la de las sociedades cooperativas de producción radica en la comercialización de bienes y servicios para obtener de ellos la mayor ganancia posible, lo que demuestra que dichas entidades no se ubican objetivamente en un plano de igualdad y, por ende, no deben recibir el mismo tratamiento jurídico." (SCJN, 2005: 350).

Lo que es claro, es que la cooperativa de producción no queda incluida entre las personas morales con fines no lucrativos a que se refiere la Ley del Impuesto Sobre la Renta (2016), lo que resulta inequitativo, toda vez que se trata de una figura jurídica con la que esencialmente busca el beneficio común, de la misma manera que las cooperativas dedicadas al consumo y al ahorro y préstamo.

Consecuentemente, la diferenciación que se hace de las cooperativas de producción, es el resultado de reformas recientes al Impuesto Sobre la Renta, las que se han encaminado a gravar y establecer medidas de control que tienen su antecedente en el uso indebido de que ha sido objeto dicha organización social, pues se ha empleado para llevar a cabo precarización laboral y evasión fiscal (Lara y Rico, 2008).

En síntesis, puede expresarse que las cooperativas son consideradas como entidades no lucrativas por la Ley General de Sociedades Cooperativas (2018), al integrar en sus disposiciones la existencia del acto cooperativo y dicha calificación es extensiva para los organismos que agrupan a las dedicadas al ahorro y préstamo. Asimismo, con la de la Ley del Impuesto Sobre la Renta (2016), se libera de dicho impuesto a las cooperativas de consumo y de ahorro y préstamo; beneficio que no alcanza a la totalidad a las cooperativas de producción, especificando que se encuentra sujeta al gravamen a la renta, destinando algunos incentivos a las sociedades dedicadas a actividades primarias (Figura 1). 
Figura. 1. Las cooperativas lucrativas y no lucrativas, según la legislación tributaria en México.

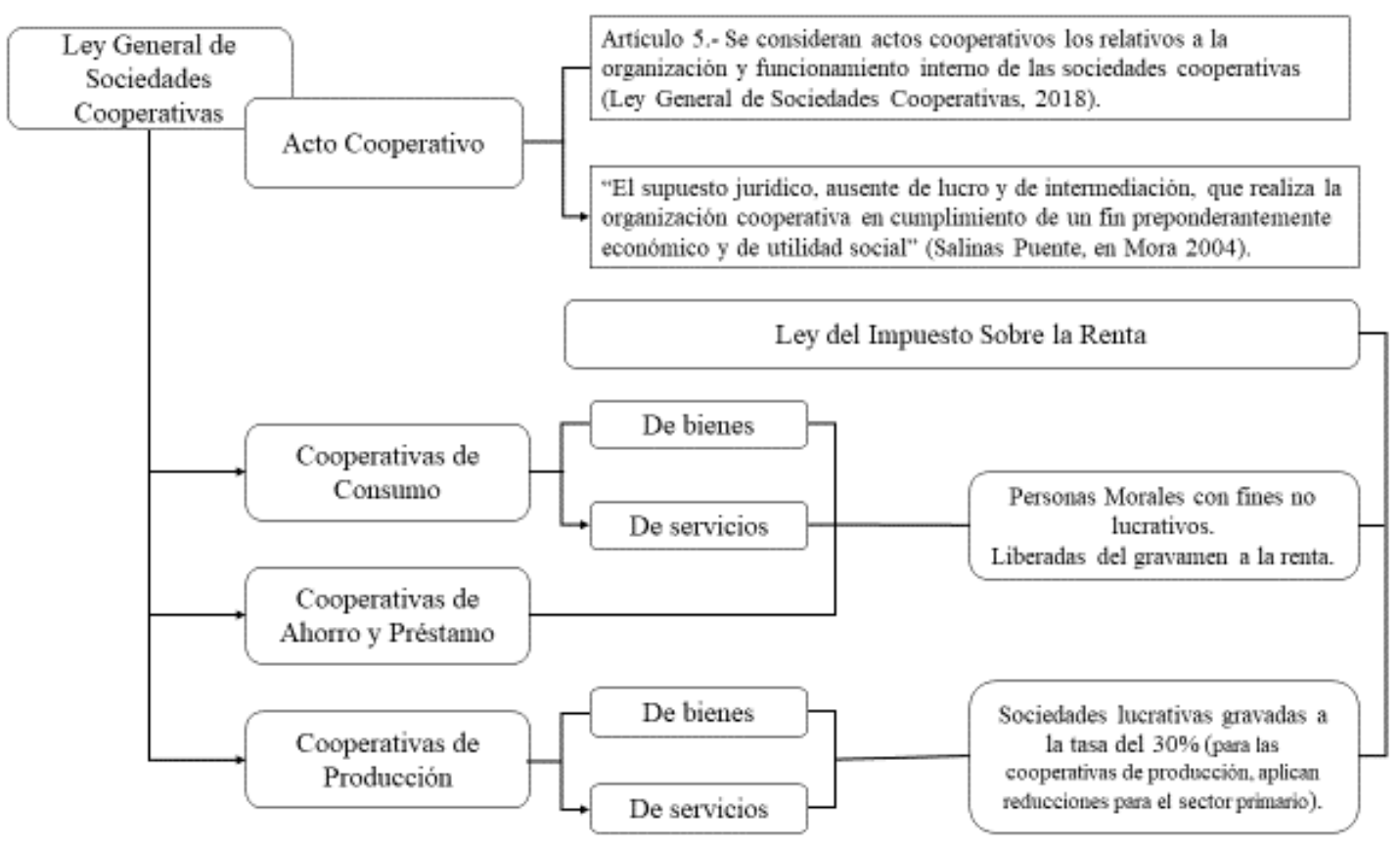

Fuente: Elaboración propia.

Con lo expuesto, puede afirmarse que el reconocimiento pleno para las cooperativas como entidades no lucrativas no se menciona expresamente en la Constitución, pero si se hace en las leyes cooperativas y en la norma en materia del gravamen a la renta, pero dicho reconocimiento es parcial, dado que solo dos figuras jurídicas están exceptuadas del pago del Impuesto Sobre la Renta por la diferenciación hecha a las cooperativas de producción. Al respecto, debe recordarse a Rodrigo (2003) quien ha expresado que de ninguna forma puede concebirse la aplicación de un tratamiento uniforme a las cooperativas y a las empresas capitalistas, pues existen motivaciones de fondo apoyadas en la justicia que justifican un trato específico.

Por tanto, las cooperativas son entidades no lucrativas y tienen un papel relevante en la sociedad al promover su cohesión, empleabilidad, la solución de problemas comunes a través de la solidaridad y la democracia, roles que son propios de las sociedades no lucrativas. No obstante, en el tema tributario dicha mención no alcanza un tratamiento equitativo entre ellas, dado que existe un esquema diferenciado que le permite imponer un gravamen a la renta para las cooperativas de producción y libera a las cooperativas de ahorro y préstamo y a las cooperativas de consumo, situación que ha sido validada por criterios de la Corte.

\section{Conclusiones}

Las cooperativas constituyen un instrumento por el que es posible mejorar la vida de sus integrantes mediante la práctica de principios y valores, con ello, es factible lograr mejoras económicas y sociales para las comunidades, sentando las bases para la construcción de una sociedad más igualitaria. Por su relevancia en el desarrollo económico y social de México, con el artículo se buscó establecer si las cooperativas mexicanas como parte del sector social de la economía, son contempladas como entidades sin fines de lucro en los ordenamientos constitucionales y legales que resultan en beneficios fiscales.

Por tanto, derivado del análisis realizado, fue posible llegar a las siguientes conclusiones:

1. La Ley General de Sociedades Cooperativas (2018) no menciona literalmente la condición no lucrativa de las cooperativas, pero si se reconoce la existencia del acto cooperativo al interior de tales sociedades.

2. La LRASCAP (2009) como una legislación específica para las cooperativas de ahorro y préstamo, integra en sus preceptos normativos, la naturaleza no lucrativa para estas sociedades dedicadas a la intermediación financiera.

3. La noción teórica del acto cooperativo no es retomada en las resoluciones dictadas por la Corte, por lo que no se justifica la característica no lucrativa con apoyo en dicha propuesta doctrinal, sino que las sustenta en la naturaleza de las actividades centradas en el consumo y producción de bienes o servicios, de las personas que se ven beneficiadas. 
4. En la Ley General de Sociedades Cooperativas (2018) no se considera el supuesto de exención de tributos por la actividad habitual de las sociedades cooperativas, pero si se hace en la norma tributaria -que constituiría la ley de la materia-, por lo que en la Ley del Impuesto Sobre la Renta (2016), se ha establecido que las cooperativas de consumo, así como las de ahorro y préstamo, quedan liberadas del pago del impuesto. Dicha liberación no se aplica a las cooperativas de producción, las que se encuentran gravadas de la misma manera que las sociedades lucrativas, salvo excepciones otorgadas a ciertas actividades de producción en el sector primario.

Finalmente, debe reflexionarse en que un movimiento cooperativo fuertemente afianzado en la filosofía que defiende, como es la práctica valores y principios de la cooperación, puede posicionarse en todo el mundo, como una alternativa viable para modificar las consecuencias del modelo económico dominante y justificar la inclusión de las cooperativas en las normas jurídicas como entidades sin fines de lucro y consecuentemente otorgarles incentivos tributarios.

\section{Referencias bibliográficas}

ACI (1995) Definición de Cooperativa. Desde https://www.aciamericas.coop/Principios-y-Valores-Cooperativos-4456. Chaves, A., R. \& Monzón, J.L. (2005) La Economía Social en la Unión Europea. No. CESE/COMM/05/ 2005. El Comité Económico y Social Europeo (CESE). [En línea]. Valencia, España: Ed. Ciriec - España.

Chaves, R.; Monzón, J.L. (2001) Economía social y sector no lucrativo: actualidad científica y perspectivas. CIRIECEspaña, Revista de Economía Pública, Social y Cooperativa, No 37, pp. 7-33. https://doi.org/10.7203/ciriece.93.12901.

Cracogna, D. (2009) La legislación cooperativa en los países de México, Centroamérica y el Caribe. [En línea]. Costa Rica: Alianza Cooperativa Internacional.

Defourny, J.; Nyssens, M. (2012) El enfoque EMES de empresa social desde una perspectiva comparada. CIRIECEspaña, Revista de Economía Pública, Social y Cooperativa, No 75, pp. 7-34. https://doi.org/10.7203/ciriece.87.7180.

Diccionario de la Real Academia Española (2014) Lucro, lucrativo. Desde http://dle.rae.es/?id=NfUPNWi.

Fici, A. (2015) La función social de las cooperativas: notas de derecho comparado. REVESCO. Revista de Estudios Cooperativos, Primer Cuatrimestre, $\mathrm{N}^{\circ}$ 117, pp. 77-98. https://doi.org/10.5209/rev_reve.2015.v117.48146.

García, M. (2017) Tipos de organizaciones no lucrativas. Desde https://www.asociacionproade.org/blog/tipos-deorganizaciones-no-lucrativas/.

Izquierdo M., M. (2012) Cooperativismo en México. En Diálogos Jurídicos España - México, Cristina Pauner Ch. (editora). $1^{\text {a }}$ edición. España: Publicacions de la Universitat Jaume I, D.L. p.; cm. — (Estudis jurídics; 19).

Lara G., G. (2011) Gestión de Empresas Sociales. 1ª edición. México: Miguel Ángel Porrúa.

Lara G., G. y Rico H., A. (2008) Subcontratación en Cooperativas de Producción. Revista de la Cooperación Internacional. Órgano oficial de la Alianza Cooperativa Internacional, 2008, vol. 41, No. 2, pp. 109-122.

Marcuello S., C. (2006) Capital social en España: Aportaciones de las organizaciones no lucrativas: El caso de las ONG para el Desarrollo. [En línea]. $1^{\text {a }}$ edición. Bilbao: Fundación BVBA.

Merino, J., I. (2009) El vigente régimen fiscal de las cooperativas a la luz de las ayudas de Estado. CIRIEC-España, Revista de Economía Pública, Social y Cooperativa, pp. 109-126. https://doi.org/10.7203/ciriec-e.92.9266.

Monzón C., J. (2013) Empresas sociales y economía social: perímetro y propuestas metodológicas para la medición de su impacto socioeconómico en la U.E. Revista de Economía Mundial, $\mathrm{N}^{\circ}$ 35, pp. 151-163.

Mora P., A. (2004) Carácter no lucrativo de las empresas cooperativas. Desde http://extension.comteco.com.bo/documentos/descargas/Alberto\%20Mora\%20(Caracter\%20no\%20Lucrativo\%20E mpresas\%20Coops).pdf.

Naranjo M., C. (2016) El Acto Cooperativo: Concepto estratégico para el desarrollo cooperativo, incorporación y tratamiento en los países de las Américas, Desde https://www.aciamericas.coop/IMG/pdf/carlosnaranjo.pdf.

NIF (2018) Normas de Información Financiera. México: Consejo Mexicano de Normas de Información Financiera.

Pastor del P., M. C. (2012) Competitividad de las cooperativas y régimen fiscal específico: el incentivo por objetivos. CIRIEC-España, Revista de Economía Pública, Social y Cooperativa. $\mathrm{N}^{\circ} \quad 23$, pp. 97-120. https://doi.org/10.7203/ciriec-e.90.8854.

Perdomo F., J. (2007) Las entidades no lucrativas. Necesidades de los usuarios de la información financiera. Revista Española del Tercer Sector, $\mathrm{N}^{\mathrm{0}}$ 7, mayo - agosto, 2007.

Rodrigo, R., M.A. (2003) Mandato constitucional de fomento y fiscalidad de las cooperativas. CIRIEC-España, Revista de Economía Pública, Social y Cooperativa, № 47, pp. 199-219. https://doi.org/10.7203/ciriec-e.92.9266.

Ruiz O., J.I. (2001) El sector no lucrativo en España. CIRIEC-España, Revista de Economía Pública, Social y Cooperativa, $\mathrm{N}^{\circ}$ 37, pp. 51-78. https://doi.org/10.7203/ciriec-e.95.13002.

Salinas R., F.; Rubio M., M. (2001) Tendencias en la evolución de las organizaciones no lucrativas hacia la empresa social. CIRIEC-España, Revista de Economía Pública, Social y Cooperativa, $\mathbf{N}^{\circ}$ 37, pp. 79116. https://doi.org/10.7203/ciriec-e.85.7625. 
Wolters Kluwer, $\quad$ (s.f.) $\quad$ Entidad no $\quad$ lucrativa. Desde http://diccionarioempresarial.wolterskluwer.es/Content/Documento.aspx?params=H4sIAAAAAAAEAMtMSbF1jT AAASNjUxNLtbLUouLM_DxbIwMDS0NDA1OQQGZapUt-ckhlQaptWmJOcSoAknsQHjUAAAA=WKE.

\section{Anexo legislativo}

Constitución Política de los Estados Unidos Mexicanos (2018) Cámara de Diputados del H. Congreso de la Unión. Diario Oficial de la Federación, 2018. Desde http://www.diputados.gob.mx/LeyesBiblio/pdf/1_270818.pdf.

Ley del Impuesto Sobre la Renta (2016) Ley del Impuesto Sobre la Renta. Diario Oficial de la Federación, H. Congreso de la Unión. Acceso el 28 de febrero de 2016. http://www.diputados.gob.mx/LeyesBiblio/pdf/LISR_301116.pdf.

Ley General de Sociedades Cooperativas (2018) Diario Oficial de la Federación, 2018. H, Congreso de la Unión. http://www.diputados.gob.mx/LeyesBiblio/pdf/143.pdf.

LGSM (2018) Ley General de Sociedades Mercantiles (última reforma). Diario Oficial de la Federación, 2018. H, Congreso de la Unión. Desde http://www.diputados.gob.mx/LeyesBiblio/pdf/144_240118.pdf.

LRASCAP (2009) Ley para Regular las Actividades de las Sociedades Cooperativas de Ahorro y Préstamo. Diario Oficial de la Federación, 2009. H, Congreso de la Unión. Desde http://www.diputados.gob.mx/LeyesBiblio/pdf/LRASCAP_280414.pdf.

SCJN (2002) Suprema Corte de Justicia de la Nación. Renta. La exención a que se refiere el artículo 10-B, segundo párrafo, de la ley que regula el impuesto relativo, no transgrede el principio de equidad tributaria por excluir de ese beneficio fiscal a las sociedades cooperativas de producción de servicios. Segunda Sala, Semanario Judicial de la Federación y su Gaceta, Tomo XV, marzo de 2002, Tesis 2a/J. 16/2002, pág. 297. Desde https://sjf.scjn.gob.mx/sjfsist/Documentos/Tesis/1001/1001973.pdf.

SCJN (2005) Suprema Corte de Justicia de la Nación Renta. Los artículos 93 y 95, fracción VII, de la ley del impuesto relativo, al no incluir a las sociedades cooperativas de producción en la exención prevista para las de consumo, no violan el principio de equidad tributaria (legislación vigente en 2002). Segunda Sala, Semanario Judicial de la Federación y su Gaceta, Tomo XXI, febrero de 2005, Tesis $2^{\mathrm{a}}$ XV/2005, pág. 350. Desde http://sjf.scjn.gob.mx/SJFSist/Documentos/Tesis/179/179204.pdf.

SCJN (2012) Suprema Corte de Justicia de la Nación. Sociedad Cooperativa: Sus características. Tesis aislada. I.3o.C.1038 C (9a.). Núm. de Registro: 159893. Libro XV, diciembre de 2012, Tomo 2, pág. 1566.Tribunales Colegiados de Circuito. Semanario Judicial de la Federación y su Gaceta. Desde http://sjf.scjn.gob.mx/sjfsist/Documentos/Tesis/159/159893.pdf. 